\title{
Implementation of an Object Detector \& Wireless Signal Transmission System
}

\author{
S M Salim Reza, Wahidul Hasan, Dilshad Ara Hossain
}

\begin{abstract}
Present Era is completely a technological age. There are so many instruments or devices are invented day by day which are used in our everyday life. Security has now become an important fact. To secure our residences, industries \& bank (where higher security is required) - an "object detection \& wireless signal transmission" circuit is designed. Using this circuit we will be able to protect our valuable things and make our life secured \& safe. The circuits consist of NE555 timer, capacitor, diode, inductor, transistor, sound chip, speaker, led, resistor, IR led, TSOP 1738, 32 $\mathrm{KHz}$ crystal, trimmer, $4069 \mathrm{UB}$. In this project, there are four sections:
\end{abstract}

- IR transmitter circuit

- IR receiver circuit

- Frequency transmitter circuit

- $\quad R F$ receiver circuit

The proposed design has various desirable features such as low cost, simpler control and maintenance, and good efficiency.

Keywords-Wireless, TSOP 1738, 4069UB, NE555

\section{i. Introduction}

One of the most common questions that rise in human mind is this: should security system be based on automatic or manual methods? The major advantage of automatic security system is that it saves manual labor, hoards energy and also improves quality, accuracy and precision [11]. So in this paper a cost effective and space saving security system named "object detection \& wireless signal transmission" for home, office and industry is designed and implemented.

The system can be implemented in a various way. First of all, in our houses, various types of expensive good are kept in locker, which are set in the different rooms of our houses. So, to avoid unwanted circumstances the system can be set to this locker. If anyone enters in the room \& come in front of the locker the system will transmit a signal about the existence and will notify it by receiving the signal in RF receiver that

S M Salim Reza

Universiti Kebangshaan Malaysia

Malaysia

Wahidul Hasan

Department of Electrical \& Electronic Engineering, Independent University

Dhaka, Bangladesh

Dilshad Ara Hossain

Dhaka, Bangladesh can be located in bedrooms of the owner in the same house and thus $\mathrm{He}$ will be notified about the existence of that person with the sound of alarm. This system is very effective at night because you can't check out your locker whole night. Secondly, it can be utilized in the main gate of our houses. If the system is set in the main gate and someone comes in front of it, the system will notify us by alarming. The receiving capacity of it might be $1^{\text {st }}$ floor to $2^{\text {nd }}$ floor. In a wide implementation, it can be used in security of banks, laboratories, document offices etc.

The main objective of this project is:

a) To eliminate human monitoring.

b) To ensure the security.

c) Building the project with minimum cost.

\section{ii. Literature Review}

This system works when any intruder passes in front of The Infrared ray transmission system, the Infrared ray waves hits the intruder and the ray comes back at some angle. This Infrared ray makes active the frequency transmitter system. At that time the system generates a signal which detects by the RF receiver circuit and that turns on security buzzer which helps to prevent any unfair entrance. The total system of the design contains three parts: (1) Infrared ray transmitter system (2) Infrared ray detection and Frequency transmitter system (3) RF receiver system. The whole system is shown in Fig. 1, 2, 3. The major advantages of this project are to eliminate human monitoring, ensure the security, and implementing the project with minimum cost.

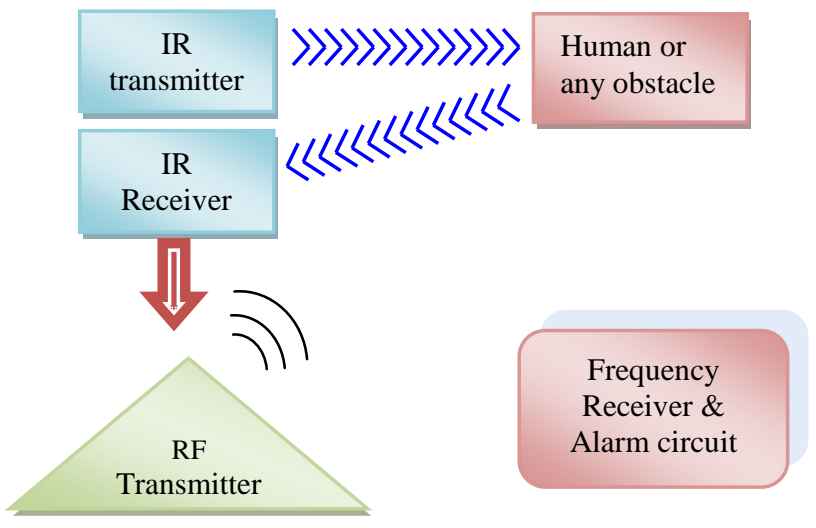

Figure 1: Block Diagram of Object detector \& wireless signal transmission system 


\section{iii. Object Detection and Signal Transmission Process through the System}

\section{IR Transmission:}

The IR led keeps transmitting infrared ray up to some distance, when any object / person comes in the IR infrared range, the IR waves hits the object / person and the ray comes back at some angle.IR receiver module (TSOP 1738) detects that IR rays. The TSOP 1738 module only can detect an IR ray of $38 \mathrm{KHz}$ frequency. The IR Transmission circuit is illustrated in fig. 3.1 .

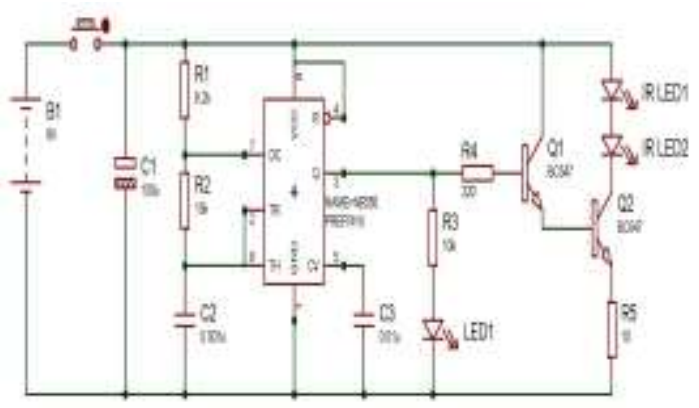

Fig. 1.1: The IR Transmission circuit

\section{Object Detection \& Signal generation[6][7][5]}

IR receiver module (TSOP 1738) detects that reflected IR rays. (The TSOP 1738 module only can detect an IR ray of $38 \mathrm{KHz}$ frequency) After that the output terminal of IR receiver module activates the BC558 transistor. This pnp transistor activates the $303 \mathrm{MHz}$ frequency transmitter circuit.

The transmitter circuit is made up of two building blocks - the $303 \mathrm{MHz} \mathrm{RF}$ oscillator and the $32 \mathrm{KHz}$ crystal controlled oscillator. The $303 \mathrm{MHz}$ oscillator consists of a self-oscillating circuit made up of the coil on the PC board and a 9pf capacitor (actually $4 p$ and $5 p$ in parallel). The circuit starts-up by the transistor producing noise. This rising-and-falling signal on the collector is passed to the parallel tuned circuit and the base sees a very smooth sine wave at a frequency of $303 \mathrm{MHz}$. This sine wave is then amplified by the transistor and this is how the $303 \mathrm{MHz}$ frequency is generated. Now we come to the purpose of the 10 microhenry choke on the tank circuit. When the circuit oscillates, it takes a larger and small amount of current. .

This current passes through the choke and the turns produce a back-emf or back voltage that fights against the flow (change) in current. The end effect is a voltage created at the point where the choke is connected to the track-work on the board. This effectively allows the track work to produce a waveform and since the frequency of this wave is very high, a percentage of the energy is radiated into the air as electromagnetic energy. The choke allows the track-work to effectively rise and fall while providing a very low resistance path for the flow of current during certain parts of the cycle. The second building block is the crystal oscillator. This is made up of a two-stage DC coupled amplifier with feedback via the 2n2 and crystal. When the crystal is added, the frequency increases (because the effect of the $2 \mathrm{n} 2$ and crystal in series creates a lower capacitance than $2 \mathrm{n} 2$ ) and as it rises, the amplitude of the feedback signal increases until it reaches a maximum at the resonant frequency of the crystal. The crystal exhibits the lowest impedance (the highest capacitance) at the resonant frequency. This is how the circuit stabilizes at the frequency of the crystal. When the device is turned on, the $150 \mathrm{k}$ on the base of the second transistor turns the transistor on.

The third transistor has $0.65 \mathrm{v}$ on the collector and the base also receives very close to $0.65 \mathrm{v}$, via the $220 \mathrm{k}$ resistor. The third transistor is not fully turned on and it produces a small amount of noise. This noise is passed to the second transistor and appears on the collector. The collector passes this noise to the base of the third transistor and the noise very rapidly increases to a maximum. It comes to a point where the waveform above is generated and the reason why the spikes are so narrow is easy to explain.

When the middle transistor changes from an OFF state to an ON state, the capacitor will be partially charged and the voltage on the end connected to the base of the third transistor will drop about $6 \mathrm{v}$ and put a negative voltage on the base of the third transistor. This will keep it off and the middle transistor will be kept $\mathrm{ON}$ via the $150 \mathrm{k}$ base-resistor. The capacitor will gradually charge in the opposite direction via the $220 \mathrm{k}$ and $150 \mathrm{k}$ and when the base of the third transistor sees about $0.6 \mathrm{v}$, it begins to turn $\mathrm{ON}$.

This causes the middle transistor to turn OFF and the collector voltage rises. This causes the capacitor to charge and create a current-flow in the base of the third transistor. Both transistors are now turned $\mathrm{ON}$ and the capacitor charges very quickly via the $12 \mathrm{k}$ and base-emitter junction of the third transistor. This creates the very narrow high-period in the waveform. When any object is detect by the IR receiver, the RF frequency transmitter circuit produces a $303 \mathrm{MHz}$ carrier with a $32 \mathrm{kHz}$ tone. The Object detection \& Signal generation circuit is illustrated in fig 1.2.

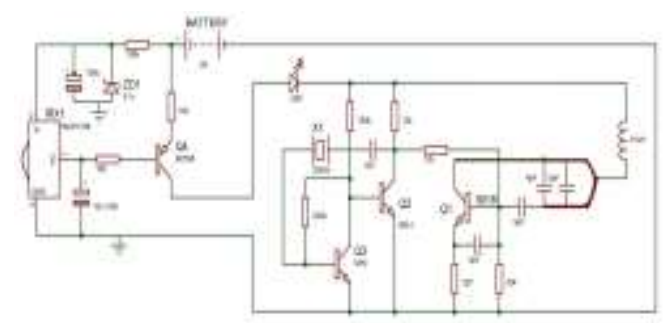

Fig 1.2: The Object Detection \& Signal generation circuit

\section{A. Signal Receiver [6][7]}

In $\mathrm{RF}$ receiver circuit the first stage is actually a $303 \mathrm{MHz}$ oscillator that is operating all the time. It produces a clean 
Proc. of The Fifth Intl. Conf. On Advances in Computing, Electronics and Electrical Technology - CEET 2016

Copyright (C) Institute of Research Engineers and Doctors, USA .All rights reserved.

ISBN: 978-1-63248-087-3 doi: 10.15224/ 978-1-63248-087-3-11

$303 \mathrm{MHz}$ signal and this frequency is too high to be detected or processed by the 4069 chip, as the chip will only operate to about $1 \mathrm{MHz}$.It is easier to "upset" or modify a stage that is already oscillating, rather than get a non-oscillating stage to begin oscillating.There are all sorts of electromagnetic radiation at $300 \mathrm{MHz}$ and the 2.5 -turns coil of receiver circuit picks up all this noise. The $303 \mathrm{MHz}$ oscillator is firstly set into operation by the noise produced by the transistor and this is passed to the tank circuit made up of the 2.5-turns coil and $2 \mathrm{p}$ capacitor as a parallel tuned circuit. The transistor keeps amplifying this until it gets to a stabilized point where the collector is producing "hash" of about $300 \mathrm{mV}$. When the transmitter is activated, the receiver circuit will detect a signal as small as a few micro-volts and the $32 \mathrm{kHz}$ signal will be included with all the other noise. There is a little bit more behind this receiving stage, than first meets the eye.The stage is actually a transmitter, but we will still call it the receiver circuit, it is a very weak transmitter and it fills the surrounding with a clean $303 \mathrm{MHz}$ signal. When the $303 \mathrm{MHz}$ signal from the transmitter enters this space, the signals interfere with one another and the receiver takes more and less current as it tries to maintain the signal strength. When the $32 \mathrm{kHz}$ signal is present, the receiver takes a varying current that corresponds to the $32 \mathrm{kHz}$ signal and this is how the receiver circuit produces the waveform to correspond to the $32 \mathrm{KHz}$.

A low-impedance path to the $0 \mathrm{v}$ rail is provided for the emitter by using a $10 \mathrm{uH}$ choke and a $2 \mathrm{n} 2$ capacitor across a $560 \mathrm{R}$ resistor. This low impedance path is needed so that the transistor has a high gain. The circuit is put into very delicate oscillation by using a $1 \mathrm{k} 5$ from the positive rail. It operates from $3.1 \mathrm{v}$ and the current taken by this stage is less than $1 \mathrm{~mA}$. The receiver is tuned to exactly the same frequency as the transmitter by changing the number of coil turns or using a trimmer instead of $2 p$ capacitor. The most critical capacitor in the receiver is the $2 p$. This sets the frequency. The $4 p$ is a feedback capacitor. The 2n2 and 1n are called "pass" capacitors and allow high frequency signals to pass through them. The $1 \mathrm{n}$ actually keeps the positive and negative rails rigid while the $2 \mathrm{n} 2$ prevents the emitter moving up and down when amplifying the $303 \mathrm{MHz}$ signal. The signal on the collector passes to the first input of the chip via a $5 \mathrm{k} 6$ resistor and 1n (pass capacitor). A lot of the high frequency component is removed with the $1 \mathrm{n}$ capacitor connected to the $0 v$ rail.

The first inverter has a $1 \mathrm{M}$ connected between the output and input to set it to mid rail so it becomes a high-gain amplifier. The second and third inverters also amplify the signal and on pin 6 we have a signal greater than $0.6 \mathrm{v}$ containing a lot of noise and an identifiable $32 \mathrm{kHz}$ waveform. The $32 \mathrm{kHz}$ crystal only allows the $32 \mathrm{kHz}$ signal to pass and the base of the transistor sees a very clean signal. Any other frequencies will not appear on the base of the transistor. The $32 \mathrm{kHz}$ is further amplified with two more stages and appears at pin 10 of the chip.

It is then passed to a diode pump that charges a $47 \mathrm{u}$ electrolytic. Normally, this electrolytic is uncharged and pin 8 is HIGH. The PNP transistor is not turned on and the sound chip is off.But when the electrolytic charges, the transistor turns on and the sound chip operates. We used an output LED instead of a sound chip.The Signal Receiver is illustrated in fig. 1.3.
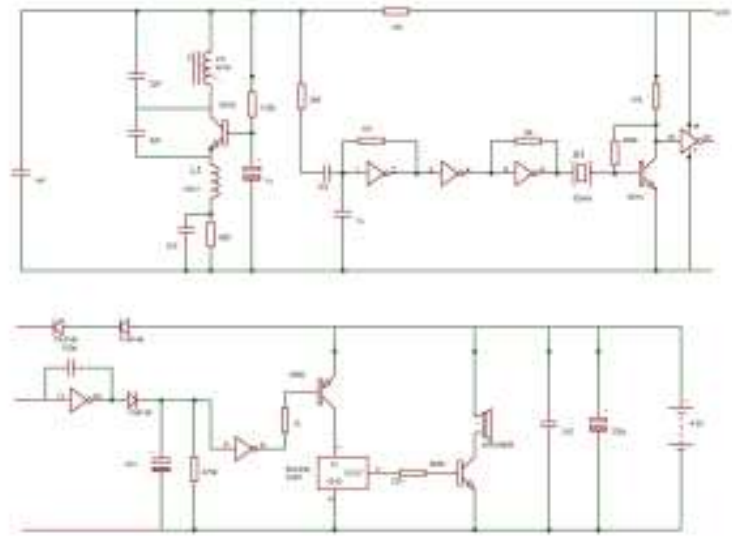

Fig. 1.3: The Signal Receiver

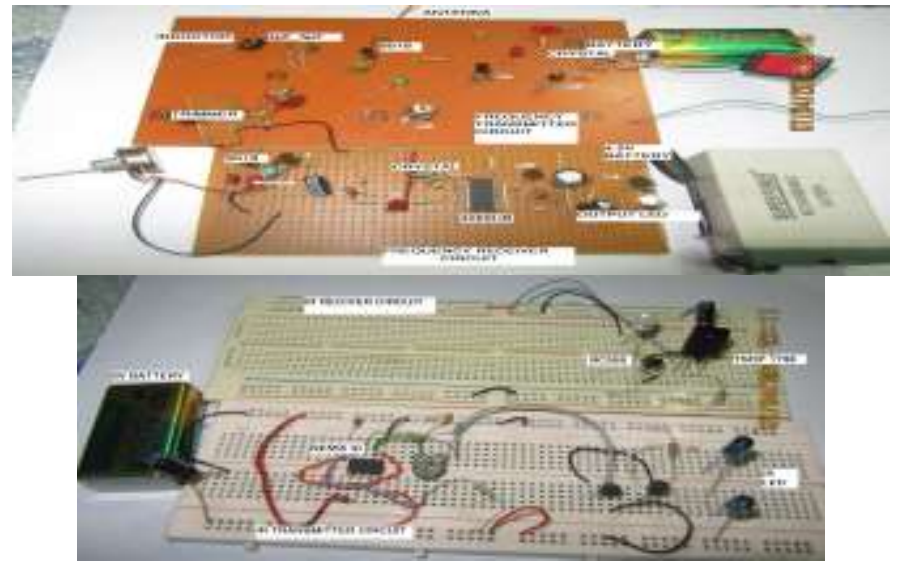

Fig. 2.1 Hard ware Implematation 
Proc. of The Fifth Intl. Conf. On Advances in Computing, Electronics and Electrical Technology - CEET 2016 Copyright (C) Institute of Research Engineers and Doctors, USA .All rights reserved.

ISBN: 978-1-63248-087-3 doi: 10.15224/ 978-1-63248-087-3-11

\section{iv. Hardware Implementation}

\section{Required Equipments}

The implemented OBJECT DETECTOR \& WIRELESS SIGNAL TRANSMISSION SYSTEM needs the following equipments:

- NE555 timer

- Battery

- 4069UB IC

- LED

- XTAL

- Transistor

- IR LED

- $\quad$ TSOP 1738

The hardware of the proposed system is shown in above Fig. 2.1

\section{NE 555}

Pin details: [5]

\begin{tabular}{|c|c|c|}
\hline Pin & \begin{tabular}{|l|} 
Name \\
\end{tabular} & Purpose \\
\hline 1 & GND & Ground reference voltage, low level $(0 \mathrm{~V})$ \\
\hline 2 & TRIG & $\begin{array}{l}\text { The OUT pin goes high and a timing interval } \\
\text { starts when this input falls below } 1 / 2 \text { of CTRL } \\
\text { voltage (which is typically } 2 / 3 \text { of } V_{\mathrm{CC}} \text {, when } \\
\text { CTRL is open). }\end{array}$ \\
\hline 3 & OUT & $\begin{array}{l}\text { This output is driven to approximately } 1.7 \mathrm{~V} \\
\text { below }+V_{\mathrm{CC}} \text { or GND. }\end{array}$ \\
\hline 4 & RESET & $\begin{array}{l}\text { A timing interval may be reset by driving this } \\
\text { input to GND, but the timing does not begin } \\
\text { again until RESET rises above approximately } 0.7 \\
\text { volts. Overrides TRIG which overrides THR. }\end{array}$ \\
\hline 5 & CTRL & $\begin{array}{l}\text { Provides "control" access to the internal voltage } \\
\text { divider (by default, } 2 / 3 V_{\mathrm{CC}} \text { ). }\end{array}$ \\
\hline 6 & THR & $\begin{array}{l}\text { The timing (OUT high) interval ends when the } \\
\text { voltage at THR is greater than that at CTRL ( } 2 / 3 \\
V_{\text {CC }} \text { if CTRL is open). }\end{array}$ \\
\hline 7 & DIS & $\begin{array}{l}\text { Open collector output which may discharge a } \\
\text { capacitor between intervals. In phase with output. }\end{array}$ \\
\hline 8 & $V_{\mathrm{CC}}$ & $\begin{array}{l}\text { Positive supply voltage, which is usually between } \\
3 \text { and } 15 \mathrm{~V} \text { depending on the variation. }\end{array}$ \\
\hline
\end{tabular}

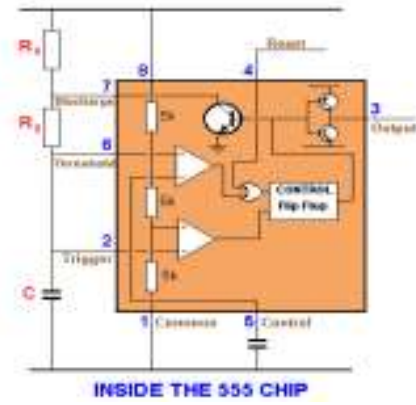

Fig.2.2: Internal view of a NE55 timer IC

The capacitor $\mathrm{C}$ charges via $\mathrm{R} 1$ and $\mathrm{R} 2$ and when the voltage on the capacitor reaches $2 / 3$ of the supply, pin 6 detects this and pin 7 connects to $0 \mathrm{v}$. The capacitor discharges through R2 until its voltage is $1 / 3$ of the supply and pin 2 detects this and turns off pin7 to repeat the cycle. The top resistor is included to prevent pin 7 being damaged as it shorts to $0 \mathrm{v}$ when pin 6 detects $2 / 3$ rail voltage. Its resistance is small compared to R2 and does not come into the timing of the oscillator.[3]

In the stable mode, the frequency of the pulse stream depends on the values of $R_{1}, R_{2}$ and $C$ :

$$
f=\frac{1}{\ln (2) \cdot C \cdot\left(R_{1}+2 R_{2}\right)}[8]
$$

The total time period, $\mathrm{T}$, is $0.693(\mathrm{R} 1+\mathrm{R} 2) \mathrm{C} 1$. [9]

The high time from each pulse is given by:

$$
\text { high }=\ln (2) \cdot\left(R_{1}+R_{2}\right) \cdot C
$$

And the low time from each pulse is given by:

$$
\text { low }=\ln (2) \cdot R_{2} \cdot C
$$

Where $R_{1}$ and $R_{2}$ are the values of the resistors in ohms and $\mathrm{C}$ is the value of the capacitor in farads.[4][8]

The graph applies to the following Astable circuit: [2]

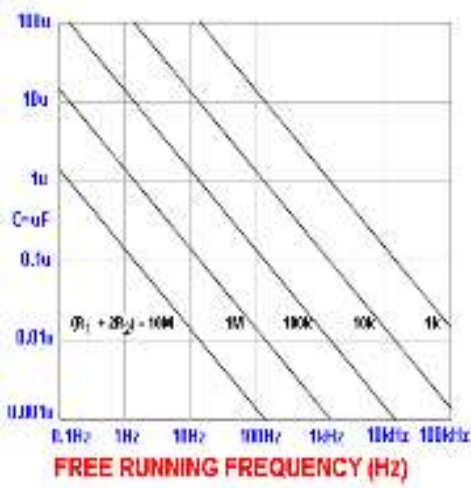

\section{B. Battery}

As the IR \& RF transmitters circuits will run on 9V DC, RF receiver circuit will operates on $3.1 \mathrm{v}$ DC so we need to use battery. It is better to use an adapter instead of a $9 \mathrm{v}$ DC battery. $220 \mathrm{~V}$ AC is converted into 9V DC through an adapter available at local market at cheap price.

\section{UB}

The 4069 contains 6 Inverters. Minimum supply voltage 3v. Maximum supply voltage 15v. Max current per output $10 \mathrm{~mA}$. Maximum speed of operation $4 \mathrm{MHz}$. Current consumption approx $1 \mathrm{uA}$ with nothing connected to the inputs or outputs.

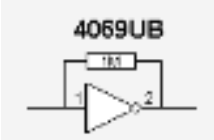

To turn an inverter into an amplifier, a $1 \mathrm{M}$ resistor is connected between input and output. Each inverter in a 4069 will amplify a very small analogue signal 
Proc. of The Fifth Intl. Conf. On Advances in Computing, Electronics and Electrical Technology - CEET 2016

(less than $1 \mathrm{mV}$ ) and produce an analogue output. It will have a gain of approx 20. [10]

\section{LED}

A light emitting diode is required to know whether the IR IRF transmitter circuit is on or off.

\section{CRYSTAL}

In RF transmitter circuit $32 \mathrm{KHz}$ crystal is used to produce a $32 \mathrm{kHz}$ noise. [6][7]

In $\mathrm{RF}$ receiver circuit the $32 \mathrm{KHz}$ crystal is used as a gate which only allows the $32 \mathrm{kHz}$ signal to pass so the receiver does not false-trigger.[6][7]

\section{Transistor [6]}

\begin{tabular}{|l|l|l|}
\hline Transistor Type: & Collector current: & Max frequency \\
\hline $8050 \mathrm{NPN}$ & $1.5 \mathrm{~A}$ & $100 \mathrm{MHz}$ \\
\hline $8550 \mathrm{PNP}$ & $1.5 \mathrm{~A}$ & $200 \mathrm{MHz}$ \\
\hline $9014 \mathrm{NPN}$ & $150 \mathrm{~mA}$ & $150 \mathrm{MHz}$ \\
\hline $9018 \mathrm{NPN}$ & $50 \mathrm{~mA}$ & $700 \mathrm{MHz}$ \\
\hline
\end{tabular}

\section{IR LED}

The IR led is used to spread out infrared ray up to some distance with a frequency of $38 \mathrm{KHz}$.

\section{TSOP 1738}

This is an IR receiver module. This is used to detect infrared ray having a frequency of $38 \mathrm{KHz}$.

\section{v. Results and Discussion}

When someone passes throughout the restricted path, RF circuit generates a signal and sends it to a distant (about 25 metres) receiver which starts to alarm at a time. Advantages of this system are

1. It will work properly at dark.

2. The transmitting stage is not affected by surrounding "stray capacitance."[6]

3. the cost of this project is very low.

There are some limitations in the system. The limitations are presented below:

1. The IR range is very low. It can detect any person below $20 \mathrm{~cm}$.

2. The system will work at slow motion.

3. The RF receiver operates with a range of 2030 metres from the transmitter circuit.

\section{PRICE LIST}

The required amount of money to implement the circuit is very low which about $\$ 4.4$ is. This cost is much lower in comparison with luxurious security systems. Total costing of the security system is listed below:

\begin{tabular}{|c|c|c|}
\hline Components & No. of quantity & Price(TK) \\
\hline NE555 & 1 & 10 \\
\hline TSOP1738 & 1 & 20 \\
\hline 32khz crystal & 2 & 30 \\
\hline resistor & 24 & 24 \\
\hline capacitor & 19 & 25 \\
\hline transistor & 10 & 30 \\
\hline IR led & 2 & 20 \\
\hline Led & 2 & 2 \\
\hline Inductor & 2 & 20 \\
\hline 4069UB & 1 & 15 \\
\hline 9v battery & 2 & 60 \\
\hline 1.5v battery & 3 & 30 \\
\hline Sound chip & 1 & 20 \\
\hline Speaker & 1 & 20 \\
\hline others & - & 24 \\
\hline total & - & $350[\$ 4.4]$ \\
\hline
\end{tabular}

\section{vi. Conclusion and Future Work}

The major ambition of this project is to maintain privacy of our home by using the modern techniques of technology. This project is a little bit different from the other projects. It's very cost effective and easy to maintain. Subsequent intentions are:

- To improve the range of IR transmitter circuit by adding an IR booster setup.

- To improve the RF transmitter circuit to get the best range from it.

\section{References}

[1] http//www.electronicsproject.com

[2] ' 100 ic circuit' a ebook by-colin mitchell

[3] http//www.talkingelectronics.com

[4] http//www.wikipedia.com

[5] http//www. diy electronics projects.com

[6] http// wirelessdoorbell.html

[7] http//www.eeweb.com

[8] van Roon Chapter: "Astable operation".

[9] http://www.edn.com/design/led/4363950/Poweran-LED-driver-using-off-the-shelf-components

[10] http//CHIP DATA.htm

[11]I. Kaur "Microcontroller based Home Security System with security," (IJACSA) International Journal of Advanced Computer Science and Applications,Vol. 1, No. 6, December 2010.

About Author (s):
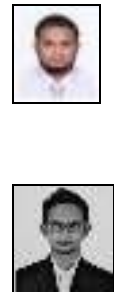

S M Salim Reza is a $\mathrm{PhD}$ Researcher at Universiti Kebangshaan Malaysia, Selangor, Malaysia. Also, he is an Assistant Professor of Bangladesh University of Professionals (BUP), Dhaka, Bangladesh.

Wahidul Hasan has he has been working as Research Assistant (RA) in the Independent University, Bangladesh (IUB), Bangladesh. 